\title{
Neonatal hearing screening of newborns of mothers with Diabetic Mellitus and/or hypertension in pregnancy: a systematic literature review
}

\author{
Luíza Silva Vernier ${ }^{1}$ \\ https://orcid.org/0000-0002-4263-9991 \\ Carla Thamires Rodriguez Castelli ${ }^{1}$ \\ https://orcid.org/0000-0002-6338-7287 \\ Daniela Centenaro Levandowski ${ }^{2}$ \\ https://orcid.org/0000-0003-1110-3614
}

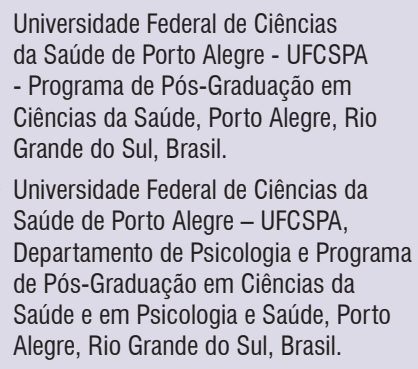

Universidade Federal de Ciências da Saúde de Porto Alegre - UFCSPA, Departamento de Psicologia e Programa de Pós-Graduação em Ciências da Saúde e em Psicologia e Saúde, Porto Alegre, Rio Grande do Sul, Brasil.

Study made in the Federal University of Health Sciences of Porto Alegre - UFCSPA, Porto Alegre, Rio Grande do Sul, Brazil.

Conflict of interests: Nonexistent

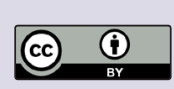

Received on: September 11, 2018 Accepted on: December 19, 2018

Corresponding address:

Luíza Silva Vernier

Rua Barbedo, 448/702, Menino Deus

CEP:90110-260 - Porto Alegre, Rio Grande do Sul, Brasil

E-mail: luiza.vernier@hotmail.com

\section{ABSTRACT}

Purpose: to investigate the results of the Neonatal Hearing Screening (NHS) in neonates whose mothers presented hypertension and/or diabetes mellitus in their pregnancy. Methods: a systematic review of the literature, without restriction of year and language, guided by the PRISMA protocol, that was carried out through a search in the MEDLINE (PUBMED), LILACS (BVS), SCOPUS, WEB OF SCIENCE and EMBASE databases, using neonatal screening AND hearing AND (hypertension OR diabetes mellitus) as descriptors. Studies that were duplicated or were unavailable were excluded.

Results: 64 records were found, 5 being included for analysis. These articles had been published in the last 13 years, originated from different countries, and using a retrospective (cross-sectional, $n=1$, case-control, $n=1$ ) or prospective design (cross-sectional, $n=1$, case-control, $n=1$; cohort, $n=1$ ). The findings of the articles demonstrated differences regarding the presence of changes in the NHS outcomes of newborns whose mothers presented hypertension and/or diabetes during pregnancy.

Conclusion: since the review showed contradictory results regarding changes in the NHS outcomes in the presence of mothers' hypertension and/or diabetes during pregnancy, prospective cohort studies are needed, in different contexts, in order to isolate confounding factors for hearing loss and minimize measurement bias and selection.

Keywords: Neonatal Screening; Hearing; Hypertension; Diabetes Mellitus; Review 


\section{INTRODUCTION}

Pregnancy is a physiological phenomenon which involves many psychosocial changes and that must be considered by the pregnant women and healthcare teams as part of a healthy life experience ${ }^{1}$. However, in the presence of medical conditions that might affect the health and/or life of the mother or the fetus (or even both), pregnancy begins to be considered a "high risk pregnancy". This term is used to indicate the presence of hazardous situations, that might occur during pregnancy, birth or post-birth, and that end up representing a bigger probability of unfavorable development of those events ${ }^{1-3}$.

Currently, $88 \%$ of the pregnancies only need basic care, as they follow a typical physiological course. However, in $12 \%$ of the cases, there is a high risk pregnancy, which requires additional and specific assistance ${ }^{2}$. The gestational diabetes and hypertension diagnoses are the ones most frequently associated with high risk pregnancy, providing additional challenges for the experiences of gestation, birth and puerperium ${ }^{1}$. Globally, 21,4 million $(16,9 \%)$ of 127,1 million live births, children of women between 20 and 49 years old, are affected by hyperglycemia upon pregnancy ${ }^{4}$. In regards to hypertension, the hypertensive disturbs are displayed from 5 to $10 \%$ of pregnancies, while preeclampsia afflicts about $3 \% 5$.

The presence of diabetes may negatively influence the intrauterine development. In the first gestational trimester, the fetus might have, as a consequence of this disease, congenital anomalies, which raises the risk of spontaneous abortion. During the second and third trimesters, excessive growth (fetal macrosomia), neonatal hypoglycemia, jaundice, polycythemia and even fetal death can be observed. Thus, this condition imposes a careful monitoring, in order to minimize the risk of fetal complications ${ }^{6,7}$. The symptoms are rare and hard to distinguish from those displayed in a low risk pregnancy, as they include the rise in thirst and frequent urination, as well as some arterial pressure elevation.

As for hypertensive diseases, they constitute a clinically challenging group, because little is known about their pathogeneses and prevention. The main consternation regarding the presence of this condition is related to the potential hazardous effects for the mother and the fetus. Furthermore, the this world spread disease don't exhibit differentiation between more or less industrialized countries ${ }^{5,8}$. Pregnancy-induced hypertension, or preeclampsia, is associated to proteinuria and edema, mainly occurring in the nulliparous after the 20th gestational week. Although it has an unknown cause, the current explicative hypothesis for its pathogenesis is that the placenta causes an abnormal immunological disturbance, resulting in the decreasing of the placental perfusion ${ }^{9}$.

Many of the physiological disturbances and complications stemming from hypertensive diseases are also associated to the presence of diabetes mellitus in pregnancy. Besides the fetal repercussions previously mentioned, both the conditions have the potential to affect the development of the auditory system and the brain of the fetus, which might lead to damages in the peripheral and/or central auditory processing. For this reason, children of diabetic mothers might be at risk when it comes to the development of communication and learning ${ }^{10}$.

Regardless of the gestational risk, it is important to guarantee the continuity of the newborn's care, assuring the follow-up care of the mother and the newborn in the postpartum, as well as along the development, so the child can reach all of the intellectual, cognitive and motor potential. In this sense, the implementation of the Neonatal Hearing Screening (NHS) represents an important step, which its goal the early detection of an auditory deficiency in newborns and infants. NHS has become a standard practice in most countries, displaying a vast available literature about benefits from financial and infant development standpoints ${ }^{11}$.

The most used technique for newborns and infants without risk indicators for hearing loss (RIHL) is the Evoked Otoacoustic Emissions (EOE) exam, characterized by being an instrument of objective pre-neural evaluation. In case the failure persists, it is advised to do the Brainstem Auditory Evoked Potential (BAEP Automatic or in screening mode), which contains an electrophysiological evaluation from the auditory nerve to the upper brainstem ${ }^{12,13}$. Regarding the presence of the diabetes mellitus and gestational hypertension, it is indicated the realization of this same sequence, as those diseases are not considered as $\mathrm{RIHL}{ }^{1,12}$, although, as mentioned before, they might affect the cerebral, and, consequently, auditory development of the fetus.

It is believed that the increase in insulin resistance, in the case of diabetes mellitus provides the fetus a large supply of nutrients needs for its growth and development, modifying the motherly levels of glucose, lipids, aminoacids and, therefore, the availability of those substrates essential for fetal development. As 
such, the change in the fetus development stemming from motherly hyperglycemia could lead to damages in the hearing development. Furthermore, many common conditions and complications in the pregnancy of diabetic women are also known as indicators for newborn hearing loss, potentially altering the development of the hearing system. However, up to now, very little is known about the auditory abilities of children born from diabetic mothers and what are the exclusive consequences to this disease on the hearing development ${ }^{10}$.As for hypertension, the initial expectation of alteration of NHS results stems from the fact that this condition, due to the systemic toxemia and vascular events, is considered as critic, for it puts both the pregnant women and the babies at risk of multiple organ failure, including the inner ear ${ }^{9}$.

Thus, the presence in those clinical conditions, and the potential auditory compromise that might entail, generate a questioning about the results obtained in the NHS by newborns whose mothers display hypertension and/or diabetes during the gestation. In this context, the current study aimed to investigate of the results of NHS of newborns whose mothers displayed hypertension and/or diabetes mellitus during pregnancy.

\section{METHODS}

To achieve the study's goals, a systematic literature review was done, based on the procedures of the Preferred Reporting Items for Systematic Reviews and Meta-Analyses (PRISMA) ${ }^{14}$ tool.The research for the articles was based on five electronic databases: MEDLINE (via PUBMED), LILACS (BVS), SCOPUS, WEB OF SCIENCE and EMBASE. In this search, the following descriptive terms were used: "neonatal screening", "hearing", "hypertension" and "diabetes mellitus", in accordance with the terms used in Health
Science Descriptors (Descritores em Ciências da Saúde - DeCS) and in Medical Subject Headings (MeSH). Specifically, the search strategy utilized was neonatal screening AND hearing AND (hypertension OR diabetes mellitus). The search used a leading question, based on the PICO methodology ${ }^{15}$. "Is there evidence of alteration (failure) in the NHS results of newborns whose mothers had hypertension and/or diabetes during pregnancy?"

The following criteria were used for the inclusion of the articles for analysis were the following: original articles, which contained the NHS results of newborns whose mothers displayed hypertension and/or diabetes during pregnancy. The language and publication date were not limited. On the other hand, all studies with duplicated entries, or that weren't fully available, were excluded.

Two researchers - audiologists - properly trained for such a goal, independently and blindly, made the queries based on the same day and date, following the same query procedures. After the registry identification $(n=64)$, all the available titles and abstracts were read to verify the article analysis inclusion criteria. Thirty studies that had their entries duplicated were excluded. Also, studies that didn't have their abstracts up for reading $(n=2)$, or that did not answer to the goal of the present study $(n=24)$, which characterizes as going off topic. It is highlighted that, during the entire article selection process, eventual disagreements over the inclusion/ exclusion of entries were resolved by discussion with a third researchers.

With the included articles $(n=8)$ in hand, the analysis of the full texts proceeded. From that reading, it was pointed out that three articles did not follow the inclusion criteria in regards to the theme. Thus, five $(n=5)$ articles were used for the analysis. The entire process of search and selection of the articles is described in Figure 1. 


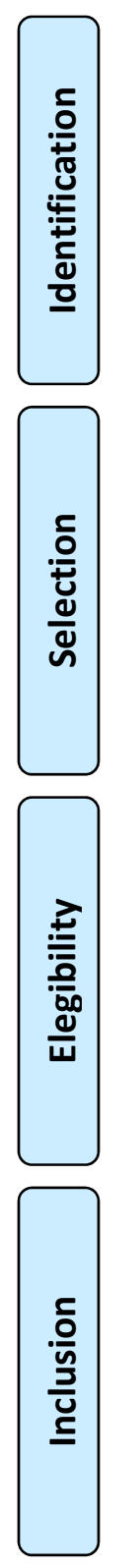

Based on Preferred Reporting Items for Systematic Reviews and Meta-Analyses ${ }^{14}$

Figure 1. Article selection flowchart

As previously mentioned, the selected articles $(n=5)$ were fully read, aiming to identify the relevant information, corresponding to authorship data (year of publication, periodic, country of publication), methodological characteristics (study research and design, sample, gestational disease), technique/ intervention used (NHS) and results from the baby's hearing evaluation. Such information was collected via standardized surveys, by both researchers, also made in independent and blind ways. For the methodological analysis of the selected studies, the recommendation of strength of the evidence Degree of the Brazilian Medical Association ${ }^{16}$ was used.

\section{LITERATURE REVISION}

Table 1 displays in detail the characterization of the analyzed studies.

In regards to the publication date of the studies not limited in the searches - there were entries from January 1975 to November 2015. However, the prevalence of entries from the last decade is highlighted: $2002(n=1), 2005(n=1), 2008(n=1)$ and $2014(n=2)$. As for the studies' origin countries, such investigations were conducted in the USA $(n=2)$, Iran $(n=1)$, Israel $(n=1)$ and Spain $(n=1)$. The authors were, in their majority, pediatricians and otolaryngologists, 
Table 1. Detailed characterization of the revised studies

\begin{tabular}{|c|c|c|c|c|c|c|c|c|}
\hline $\begin{array}{c}\text { Publication } \\
\text { Year }\end{array}$ & Journal & Country & Purpose & Design & Sample & $\begin{array}{l}\text { Gestational } \\
\text { Disease }\end{array}$ & $\begin{array}{l}\text { Technique/ Intervention } \\
\text { (NHS) andage of the } \\
\text { evaluated newborns }\end{array}$ & Results \\
\hline 1. $2014^{17}$ & $\begin{array}{l}\text { Acta } \\
\text { Otorrinolarin- } \\
\text { gológica } \\
\text { Española }\end{array}$ & Spain & $\begin{array}{l}\text { To know the influence of } \\
\text { diverse perinatal factors } \\
\text { in response to the EOEs } \\
\text { on the first } 48 \mathrm{~h} \text { of life. }\end{array}$ & $\begin{array}{l}\text { Retrospective } \\
\text { Transversal }\end{array}$ & $\begin{array}{c}\text { n total: } 8.239 \\
\text { n diabetes: } 162 \\
\text { n hypertension:77 }\end{array}$ & $\begin{array}{l}\text { Diabetes } \\
\text { Mellitus } \\
\text { Hypertension }\end{array}$ & $\begin{array}{l}\text { The EOE type was not } \\
\text { specified } \\
\text { Made around the first } 48 \\
\text { hours of the newborn's life }\end{array}$ & $\begin{array}{l}\text { Diabetes: } p<0,98 \\
\text { Hypertension: } p<0,32 \\
\text { No significant relation between } \\
\text { diabetes or hypertension and } \\
\text { the EOE. }\end{array}$ \\
\hline 2. $2014^{18}$ & Harefuah & Israel & $\begin{array}{l}\text { To verify the effect } \\
\text { of medicaments and } \\
\text { maternal diseases } \\
\text { during pregnancy over } \\
\text { the results of the first } \\
\text { EOE tests. }\end{array}$ & $\begin{array}{l}\text { Prospective } \\
\text { Transversal }\end{array}$ & $\mathrm{n}$ total: 2306 & $\begin{array}{c}\text { Diabetes } \\
\text { Mellitus } \\
\text { Hypertension }\end{array}$ & $\begin{array}{l}\text { The EOE type was not } \\
\text { specified } \\
\text { Made between } 12 \text { and over } 48 \\
\text { hours of the newborn's life }\end{array}$ & $\begin{array}{c}\text { Diabetes and vaginal delivery: } \\
\text { [OR } 2.2(1.0-4.84) p=0.049] \\
\text { Hypertension/preeclampsia } \\
\text { and cesarean section: [OR } 2.3 \\
(1.22-4.3) p=0.01] \\
\text { There was significant } \\
\text { relation between diabetes or } \\
\text { hypertension and EOE failings }\end{array}$ \\
\hline 3. $2008^{9}$ & $\begin{array}{l}\text { Otolaryngology } \\
\text { - Head and } \\
\text { Neck Surgery }\end{array}$ & Iran & $\begin{array}{l}\text { To determine the } \\
\text { probable prevalence } \\
\text { of hearing deficiency } \\
\text { of children whose } \\
\text { mothers had induced } \\
\text { hypertension during } \\
\text { pregnancy, in } \\
\text { comparison to those } \\
\text { born from healthy } \\
\text { mothers. }\end{array}$ & $\begin{array}{l}\text { Prospective } \\
\text { Cohort }\end{array}$ & $\begin{array}{c}\mathrm{n} \text { total: } 150 \\
\text { n hypertension: } 36 \\
\text { n healthy: } 114\end{array}$ & Hypertension & $\begin{array}{c}\text { TEOAE } \\
\text { Made after birth. In case of } \\
\text { failure, made again two weeks } \\
\text { after birth. } \\
\text { BAEP } \\
\text { Made after failure in the } \\
\text { second TEOAE test, until the } \\
\text { end of the newborn's first } \\
\text { month of life. }\end{array}$ & $\begin{array}{l}\text { FirstTEOAE: }(p=0.001) \\
\text { Second TEOAE: }(p=0.646) \\
\text { BAEP: }(p=0.573) \\
\text { This study suggests that } \\
\text { preeclampsia might have } \\
\text { some temporary effect over } \\
\text { the hearing of newborns. }\end{array}$ \\
\hline 4. $2005^{10}$ & $\begin{array}{l}\text { American } \\
\text { Journal of } \\
\text { Audiology }\end{array}$ & USA & $\begin{array}{l}\text { To compare the NHS } \\
\text { results of newborns } \\
\text { whose mothers had pre- } \\
\text { gestational diabetes with } \\
\text { non-diabetic mothers. }\end{array}$ & $\begin{array}{l}\text { Retrospective } \\
\text { Case-control }\end{array}$ & $\begin{array}{c}\text { n total: } 146 \\
\text { n diabetes: } 73 \\
\text { n healthy: } 73\end{array}$ & $\begin{array}{l}\text { Diabetes } \\
\text { Mellitus }\end{array}$ & $\begin{array}{c}\text { DPOAE } \\
\text { BAEP-A } \\
\text { Doesn't specify the lifetime } \\
\text { used of the NHS realization - } \\
\text { according to protocol }\end{array}$ & $\begin{array}{l}\text { DPOAE: } 5,5 \% \text { (4/73) for } \\
\text { the babies of the control } \\
\text { groups (non-diabetic), and } \\
11,0 \% \text { ( } 8 / 73 \text { ) for infants of } \\
\text { diabetic mothers. There was } \\
\text { no significant relation for the } \\
\text { failing, after the comparison } \\
\text { of the groups (x2 = 0.82, } p \\
=0.37 \text { ). } \\
\text { BAEP-A: } 9,1 \%(1 / 11) \text { for the } \\
\text { group of diabetic patients in } \\
\text { comparison to 0\% (0/4) for } \\
\text { the control groups. Despite } \\
\text { not displaying the p value, the } \\
\text { article explains that there was } \\
\text { no significant relation. }\end{array}$ \\
\hline $5.2002^{19}$ & $\begin{array}{l}\text { American } \\
\text { Journal of } \\
\text { Audiology }\end{array}$ & USA & $\begin{array}{l}\text { To identify potential risk } \\
\text { factors for newborn } \\
\text { hearing loss that is not } \\
\text { included in the variables } \\
\text { recognized by the } \mathrm{JCIH} \text {. }\end{array}$ & $\begin{array}{l}\text { Prospective } \\
\text { Case-control }\end{array}$ & $\begin{array}{c}\text { n total: } 746 \\
\text { n cases: } 110 \\
\text { n controls: } 636\end{array}$ & $\begin{array}{l}\text { Diabetes } \\
\text { Mellitus }\end{array}$ & $\begin{array}{c}\text { BAEP } \\
\text { Doesn't specify the lifetime } \\
\text { used of NHS realization - } \\
\text { according to protocol }\end{array}$ & $\begin{array}{c}\text { Diabetes: }(p=0.011) \\
\text { There was significant relation } \\
\text { between the presence of } \\
\text { maternal diabetes and } \\
\text { newborn BAEP failure. }\end{array}$ \\
\hline
\end{tabular}

Abbreviations: $\mathrm{OR}=$ odds ratio; $\mathrm{EOE}=$ Evoked Otoacoustic Emissions; TEOAE $=$ Transient Evoked Otoacoustic Emissions; DPOAE $=$ Distortion Product Evoked Otoacoustic Emissions; BAEP=Brainstem Auditory Evoked Potential; BAEP-A=Brainstem Auditory Evoked Potential - automatic; $p=p$ value

as expected, for those professional are able to make the tests in their respective countries. In this sense, the journals in which the articles were published were directed to the medical field, especially otorhinolaryngology and audiology, and ranged within the QUALISCAPES rating from $A 2$ to $B 4$ (Collective Health: $B 1$ and B2; Medicine I: B1 and B4; Physical Education: A2), according to the parameters of this evaluation in the year of 2015.

The goals of the analyzed articles displayed similarities, such as the focus on the attention to the hearing of newborns and in the search for possible associations between gestational diseases and hearing loss in newborns, aiming to promote the early attention to pregnant women's health, as well as verifying possible hearing losses in newborns. The lack of Brazilian articles focusing on this theme draws attention, making evident the need of researches of this nature in the national context.

As for the variables analyzed in the revised studies, a great diversity was observed, including perinatal factors, sociodemographic data and maternal/neonatal diseases. An isolated evaluation for each variable would bring more reliability for the results found, especially in the association between diabetes mellitus and/or hypertension during pregnancy and congenital hearing loss. 
Due to the nature of the studies' goals, in regards to the methodological characteristics, the predominance of prospective studies $(n=3)$, with cross-sectional design, case control or cohort was observed. Those, according to the recommendation and strength of evidence degrees, analyzing the design, of the Brazilian Medical Association ${ }^{16}$, ranged between $B$ and $C$. The absence of A-ranked articles shows that randomized clinical trials could be used to reduce biases, although, in order to achieve a better reliability in relation to the NHS conclusions and its possible associations with hypertension and/or diabetes mellitus, it is understood that the prospective cohort studies is the most indicated.

As for the technique used for the NHS, a predominance in the revised studies, of the technique postulated by the $\mathrm{JCIH}^{12}$ : the TEOAE, was observed. Due to the absence of RIHL amongst the diseases that were the focus of the present study, the EOE ${ }^{1}$ were employed in different categories-mainly TEOAE, although DPOAEs was also used. Some articles showed the sequence of EOE followed by BAEP. It is worth pointing out that those evaluation forms have their differences. For instance, the TEOAE and the DPOAE are used for the monitoring of the cochlear function and have a good sensibility and specificity ${ }^{13}$. TEOAE is an objective, fast, and non-intrusive method, which does not demand the placement of electrodes, indicated for the NHS, with a wide spectrum that covers an array of frequencies. The DPOAE, on the other hand, is characterized by the stimulation via simultaneous presentation of two pure tones which, by intermodulation, produce a third product as answer.

Besides that, four of the five selected articles described the equipment used for the NHS. The equipment were: Otoport Lite, Otodynamics Ltd; GSI Audio Screener, Grason-Stadler; GN Otometrics; Bio-logic AudX II, Natus; ALGO 2 Newborn Hearing Screener, Natus; and Echocheck EOE Screener, Otodynamics Ltd. A great diversity of used equipment can be observed. Thus, a reference bias might have happened, which led to the difference in the analyzed studies, due to the employment of different evaluation measures, with different equipment.

In this direction, in regards to the revised studies, that is, the NHS results of newborns whose mothers had diabetes mellitus and/or arterial hypertension, contradictions were found. In the study that related hypertension during pregnancy to the NHS results, in 2008, researchers ${ }^{9}$ presented that hypertensive symptoms can put labor forward, indicating the possibility of prematurity, and consequently the diseases associated with it, which could cause neural-sensorial hearing loss. Amongst its findings, on the first TEOAE evaluation, it was pointed out that 12 of the 36 cases $(33.33 \%)$ and 12 of the 102 controls (11.76\%) presented failure. There was a statistically significant difference (value $p=0.001$ ), but on the retest with TEOAE, followed by BAEP, two and four weeks later respectively, no significant changes between the groups were observed. In short, the study does not relate permanent sensory-neutral hearing loss with the presence of hypertension, unless when it leads to prematurity complicated by intracranial hemorrhage or severe anoxia, or other conditions subject to association. In another study ${ }^{18}$ which addressed maternal hypertension, an association with the failure in the newborn's EOE was found.

Also in regards to diabetes mellitus, the results from revised studies were inconclusive. For instance, a 2005 study $^{10}$ proposed that children born from diabetic mothers needed attention, for other diseased that stem from this condition, such as hypoxia, hyperbilirubinemia and iron deficiency, that have specific mechanisms which enhance the risk of disorders in the neurological development and hearing system dysfunction. However, it wasn't possible to identify, in this study, the difference between the DPOAE failures due the presence of gestational diabetes mellitus. This way, the authors highlighted the necessity to evaluate the metabolic alterations caused by diabetes, as well as differentiating gestational diabetes from pre-gestational diabetes. On the other hand, researchers, in the year of $2002^{19}$, identified a statistically significant relation between the NHS alteration and the presence of maternal diabetes as a possible risk indicator for hearing deficiency, concluding that there are potential factors that are not listed as RIHL, but that can affect the hearing of the infant population. In face of this finding, they suggested studies so that such influence can be determined.

Also, studies that jointly analyzed the presence of diabetes mellitus and hypertension and its association with newborn hearing results were analyzed. In this sense, a study made in $2014^{17}$ did not find the association between those diseases and the NHS failure, without justifying or discussing those findings, although the authors did analyze other maternal diseases.

From what was presented, it is determined that the NHS results in newborns whose mothers had diabetes 
mellitus and/or hypertension during pregnancy were revealed to be altered and not altered, thus deemed inconclusive the association between those clinical conditions and hearing impairments in newborns. While some studies did find an association between those gestational diseases and alterations in NHS results, others did not display such relation. This discrepancy among the findings can be attributed to differences in sample sizes, available variability between the studied groups, or even in the technique used for the newborn hearing evaluation, as commented earlier. In this sense, comparative studies, using the same evaluation methodology, should be conducted, considering the different diseases, with the intent of making possible a better identification of eventual association between the variables highlighted here.

\section{CONCLUSIONS}

Considering the goal of the present study, that is, to investigate NHS results of newborns whose mothers showed hypertension and/or diabetes mellitus during pregnancy, the findings of the revised studies did not allow for the confirmation of the initial expectation, guided by the pathophysiological description of those diseases, exposed in the literature, that there were evidences of auditory loss in newborns whose mothers displayed such clinical conditions in pregnancy.

Thus, from this systematic literature review, the need for empirical studies to investigate, individually, each of those gestational conditions, relating them with possible newborn auditory development impairment, was made explicit. Further prospective studies must be planned to examine the relation between metabolic disturbances during pregnancy and the functioning of the auditory system of newborns, especially in the Brazilian context, due to the lack of publications on this subject, in the country.

Also relevant are studies with prospective cohort design, which compare children born from mothers who displayed diabetes or pre-gestational hypertension, and children born from mothers who only showed those clinical conditions during pregnancy. In such studies, it would be recommendable to measure the gravity of those clinical conditions, control the medicaments administered to the women and standardize the newborn auditory evaluation. Furthermore, the sample control is highlighted as relevant, so that the variability among the population can be considered. It is understood that those measures could reduce or even avoid altogether confusion factors, and would allow answering the question which guided the present study with better reliability.

\section{REFERENCES}

1. Brasil. Ministério da Saúde. Secretaria de Atenção à Saúde. Departamento de Ações Programáticas Estratégicas. Gestação de alto risco: manual técnico. 5a ed. Brasília, 2010. [acesso em: 2017 jan. 10].Disponível em: http://bvsms.saude.gov.br/bvs/ publicacoes/gestacao_alto_risco.pdf

2. Coco L, Giannone TT, Zarbo G. Management of high-risk pregnancy. Minerva ginecologica. 2014;66(4):383-9.

3. Sohand MCC, Piercy N. High-risk pregnancy and the rheumatologist. Rheumatology. 2015;54(4):572-87.

4. McCance DR. Diabetes in pregnancy. Best Pract Res ClinObstetGynaecol. 2015; 29(5):685-99.

5. Hutcheon JA, Lisonkova $S$, Joseph KS. Epidemiology of pre-eclampsia and the other hypertensive disorders of pregnancy. Best Pract Res ClinObstetGynaecol. 2011;25(4):391-403.

6. Buchanan TA, Xiang AH, Page KA. Gestational diabetes mellitus: risks and management during and after pregnancy. Nat Rev Endocrinol. 2012;8(11):639-49.

7. International Diabetes Federation - Diabetes Atlas. 2015;7. [acesso em: 2016 dez. 15].Disponível em: http://www.diabetesatlas.org/

8. Mustafa R, Ahmed S, Gupta A, Venuto RC. A comprehensive review of hypertension in pregnancy. Journal of Pregnancy. 2012;2012:105918. doi: 10.1155/2012/105918. Epub 2012 May 23.

9. Bakhshaee $M$, Boskabadi $H$, Hassanzadeh $M$, Nourizadeh N, Ghassemi MM, KhazaeniKet. Hearing impairment in the neonate of preeclamptic women. Otolaryngol Head Neck Surg.2008;139(6):846-9.

10. Stanton SG, Ryerson E, Moore SL, SullivanMahoney $M$, Couch SC. Hearing screening outcomes in infants of pregestational diabetic mothers. Am J Audiol. 2005;14(1):86-93.

11. Beswick R, Driscoll C, Kei J. Monitoring for postnatal hearing loss using risk factors: a systematic literature review. Ear Hear. 2012;33(6):745-56.

12. American Academy of Pediatrics, Joint Committee on Infant Hearing $(\mathrm{JClH})$. Year 2007 position statement: principles and guidelines for early hearing detection and intervention programs. Pediatrics. 2007;120(4):898-921. 
13. Côrtes-Andrade IF, Bento DV, Lewis DR. Emissions (TEOE): newborn hearing screening program protocols. Rev. CEFAC. 2013;15(3):521-7.

14. Moher D, Liberati A, Tetzlaff J, Altman DG. The PRISMA Group (2009). Preferred Reporting Items for Systematic Reviews and Meta-Analyses: The PRISMA Statement. Ann Intern Med. 2009;151(4):264-9.

15. Santos CMC, Pimenta CAM, Nobre MRC. The PICO strategy for the research question construction and evidence search. Rev. Latino-Americana de Enfermagem. 2007;15(3):508-11.

16. Associação Médica Brasileira. [acesso em: 2016 dez. 10]. Disponível em: http://www. amb.org.br.

17. Sequi-Canet JM, Sala-Langa MJ, Catillo JIC. Factores perinatales que influyen em La detección de otoemisiones acústicas em recién nacidos sanos, por parto vaginal, em lãs primeras 48 horas de vida. Acta Otorrinolaringol Esp. 2014;65(1):7.

18. Ulanovsky I, Diab K, Makhoul IR, Blazer S, Smolkin T. The effect of maternal medications, hypertension/pre-eclamptic toxemia and diabetes mellitus on neonatal hearing screening. Harefuah. 2014;153(9):511-4.

19. Kountakis SE, Skoulas I, Phillips D, Chang CJ. Risk factors for hearing loss in neonates: a prospective study. Am J Otolaryngol.2002;23(3):133-7. 